\title{
Benign Prostat Hiperplazisi ve Antimuskarinik Tedavi
}

\section{Benign Prostatic Hyperplasia and Antimuscarinic Treatment}

Özet

Alt üriner sistem semptomları (AÜSS) terimi; üriner sistem semptomlarına sahip erkek hastaları değerlendirmede kullanılan prostatizm, semptomatik benign prostat hiperplazisi (BPH) ve klinik $\mathrm{BPH}$ terimlerinin yerini almaktadır. BPH, aşırı aktif mesane (AAM), nokturnal poliüri, üriner sistem enfeksiyonları, distal üreter taşları ve mesane tümörleri gibi birçok sağlık sorunu AÜSS'ye neden olabilir. Yaygın kullanılan bir terim olan AÜSS kapsamına giren semptomlar; depolama (acil idrar yapma hissi, sık idrara çıkma, gece idrar yapmak için uyanma ve urge inkontinans), işeme (işeme gücünde azalma, idrarı başlatmakta gecikme, kesik kesik idrar yapma) ve işeme sonrası (işeme sonrası damlama, yetersiz boşaltım hissi) ile ilgili semptomlar olarak üç alt grupta toplanmıştır. Günümüzde BPH için uygulanan en yaygın ve standart tıbbi tedavide a1-adrenerjik reseptör antagonistleri kullanılmaktadır. Bu tedavinin yetersiz kaldığı düşünülen durumlar için alternatif tedavi arayışları halen sürmektedir. Bu çalışmalar sonucunda, BPH'nin tedavisinde a 1blokerler ile birlikte kullanılan antimuskarinik ilaçlar, bir kombine tedavi olarak literatürdeki yerini almıştır. Bu derlemede; BPH'den muzdarip hastalarda antimuskarinik tedavilerinin etkinliği ve güvenilirliği değerlendirilmiştir.

Anahtar Kelimeler. BPH; muskarinik antagonistler

\begin{abstract}
The term lower tract urinary symptoms (LUTS) has been replacing the terms such as prostatism, symptomatic benign prostatic hyperplasia (BPH), and clinical $\mathrm{BPH}$ used in the evaluation of male patients with symptoms associated with the urinary system. Many health conditions including $\mathrm{BPH}$, overactive bladder ( $\mathrm{OAB})$, nocturnal polyuria, urinary tract infections, distal ureteral calculi, and bladder tumors can cause LUTS. The symptoms covered by the commonly used term LUTS are categorized into three subgroups; those associated with storage, those associated with urination, and those seen after urination. Today the standard and most common medical treatment for $\mathrm{BPH}$ is the use a 1 - adrenergic receptor blockers. However, the search for alternative treatment modalities continues, especially for situations in which a 7 -adrenergic receptor blockers are considered as insufficient. With the relevant reports in the literature, this led to the use of antimuscarinic drugs together with the a1-adrenergic receptor blockers as a combination therapy to treat $\mathrm{BPH}$. This paper reviews the effectiveness and safety of the use of antimuscarinic treatments in patients with $\mathrm{BPH}$.
\end{abstract}

Key Words: BPH; muscarinic antagonists
Mehmet Kaynar, Emre Altıntaş, Serdar Göktaş

Selçuk Üniversitesi Tıp Fakültesi, Üroloji Anabilim Dalı

Geliş Tarihi /Received : 03.03.2016 Kabul Tarihi /Accepted: 20.03.2016

Sorumlu Yazar/Corresponding Author Yrd. Doç. Dr. Mehmet Kaynar Selçuk Üniversitesi Alaeddin Keykubat Kampüsü PK: 42075

Selçuklu Konya/Türkiye

E-mail:mekaynar@gmail.com 


\section{GíRiş}

Üriner sistem semptomlarına sahip erkek hastaların daha geniş açıdan değerlendirilmesi için, prostatizm, semptomatik benign prostat hiperplazisi (BPH) ve klinik BPH terimleri yerine alt üriner sistem semptomları (AÜSS) teriminin kullanılması kabul görmüştür. BPH, aşırı aktif mesane (AAM), nokturnal poliüri, üriner sistem enfeksiyonları, distal üreter taşları ve mesane tümörleri gibi birçok sağlık sorunu AÜSS’ye neden olabilir (1). Yaygın kullanılan bir terim olan AÜSS kapsamına giren semptomlar; depolama (acil idrar yapma hissi, sık idrara çıkma, gece idrar yapmak için uyanma ve urge inkontinans), işeme (işeme gücünde azalma, idrarı başlatmakta gecikme, kesik kesik idrar yapma) ve işeme sonrası (işeme sonrası damlama, yetersiz boşaltım hissi) ile ilgili semptomlar olarak üç alt grupta değerlendirilmektedir (2). Günümüzde BPH için uygulanan en yaygın ve standart tıbbi tedavide $\alpha_{1}{ }^{-}$ adrenerjik reseptör antagonistleri kullanılmaktadır. $\mathrm{Bu}$ tedavinin yetersiz kaldığ düşünülen durumlar için alternatif tedavi arayışları halen sürmektedir. Bu çalışmalar sonucunda BPH'nin tedavisinde $\alpha_{1}$-blokerler ile birlikte kullanılan antimuskarinik ilaçlar, bir kombine tedavi olarak literatürdeki yerini almıştır (bkz. Tablo 1). Bu derlemede, BPH hastalarında mesane çıkım tıkanıklığına ( $\mathrm{MCCT}$ ) irritatif semptomların (istemsiz detrüsör kontraksiyonları olsun veya olmasın) eşlik etmesi nedeniyle antimuskarinik ilaçların monoterapi ya da kombinasyon tedavisi halinde kullanımı değerlendirilmiştir.

\section{$B P H$ ve $A A M$}

BPH nedeniyle prostat cerrahisi geçiren hastaların bir kısmında AÜSS'ye ait depolama (irritatif) semptomlarının geçmemesi, bu hastalarda obstrüksiyon dışında başka faktörlerin de olabileceğini gündeme getirmektedir. AÜSS görülen, elli yaş üzerindeki erkeklerde ürodinamik parametrelerin değerlendirildiği bir çalışmada, \%62 oranında MÇT saptanmış ve MÇT saptanan hastaların \%66’sında detrüsör aşırı aktivitesinin olduğu gözlenmiştir (3). AÜSS görülen hastaların \%68'inde MÇT ve bu hastaların da \%46'sında detrüsör instabilitesi tespit edilmiş olup, detrüsör instabilitesi olan hastaların da \%75'inde urge inkontinans saptanmıştır (4). Detrüsör instabilitesinin depolama semptomları ile ilişkili olduğu, bu çalışmada ürodinamik olarak ortaya konmuştur. Amerika Birleşik Devletleri'nde 40 yaş üzeri kişilerde AAM semptomlar1 prevalansının erkeklerde \%15,8-27,2, kadınlarda \%32,6-43,1 arasında olduğu belirtilmektedir (5). Uluslararası İnkontinans Derneğine (International Continence Society) göre AAM; urge inkontinans olsun veya olmasin urgency ile birlikte gece ve gündüz işeme sıklığının artması ve bu semptomları açıklayabilecek enfeksiyon gibi patolojik nedenlerin bulunmadığı bir sendrom olarak tanımlanmaktadır (2). AAM’nin başlıca nedeninin detrüsör aşırı aktivitesi olduğu bilinmektedir. MÇT'li erkeklerde AAM'nin ortaya çıkması ile ilgili farklı hipotezler ortaya atılmıştır. En yaygın olarak savunulan hipoteze göre MÇT vakalarının \%45-50'si, mesane iskemisine bağlı yapısal değişiklikler sonucunda ortaya çıkan kolinerjik reseptör hipersensitivitesini içine birtakım lokal faktörlerden kaynaklanmaktadır. Bununla birlikte hücrede iskelet ve mitokondrial proteinlerdeki değişikliğe bağlı kontrolsüz asetilkolin salınımının ve mesane afferent sinir elastisitesindeki değişikliklerin de MÇT’de AAM'ye neden olduğu belirtilmiştir (6). Ancak MÇT gibi periferik problemlerin yanı sıra, santral sinir sistemi lezyonları gibi bazı santral olaylar da ileri yaşlı hastalarda detrüsör aşırı aktivitesini tetikleyerek AAM'ye neden olabilmektedir. AÜSS değerlendirilmesinde ürodinamik incelemenin rutin uygulama zorluğu nedeniyle sıklıkla IPSS skorlaması kullanılmaktadır. IPSS'nin 2., 4. ve 7. sorularını oluşturan frequency, urgency, nokturia, depolama ile ilgili değerlendirmedeki IPSS subskorlarını oluşturmaktadır.

\section{Antimuskarinik tedavi}

Muskarinik reseptörler detrüsör düz kaslarında, sekretuar bezlerde, mesane ürotelyal hücrelerinde, prostat yanında periferik ve santral sinir sistemlerinde yaygın olarak bulunmaktadır. Muskarinik reseptörlerin beş alt tipi mevcuttur $\left(\mathrm{M}_{1}-\mathrm{M}_{5}\right)$. Detrüsör düz kas hücrelerinde $\% 80 \mathrm{M}_{2}, \% 20 \mathrm{M}_{3}$ muskarinik reseptörleri bulunur ve nörotransmitteri asetilkolindir. Mesane kontraksiyonlarından sorumlu olan reseptör daha çok $\mathrm{M}_{3}$ reseptörüdür. Muskarinik reseptörlerin muskarinik reseptör antagonistleri tarafından inhibe edilmesi mesane düz kas hücreleri kontraksiyonlarını inhibe eder $(7,8)$. Muskarinik reseptörlerin inhibis- 
yonu mesane düz kaslarında gevşemeye neden olarak mesanede duyu eşiğini azaltmaktadırlar. Antimuskarinik ilaçların detrüsör kontraksiyonlarını azaltmaları nedeniyle işeme zorluğu, post-voiding rezidü (PVR) idrar miktarının artışı gibi birtakım kaygılar bulunmaktadır. Ancak son yıllarda MÇT'li hastalarda antimuskarinik kullanımı ile ilgili bu soru işaretlerini kanıtlar üzerinden ortadan kaldıracak yeni çalışmalar ortaya çıkmaktadır: MÇT'li ve AAM'li 149 erkek hastada, plasebo kontrollü antimuskarinik tedavi sonrası güvenlilik ürodinamik olarak değerlendirilmiştir. $\mathrm{Q}_{\max }$ ve $\mathrm{P}_{\text {det }} \mathrm{Q}_{\max }$ değerlerinde yan etki açısından herhangi bir fark saptanmamış olup PVR'de $25 \mathrm{ml}$ artış, ortalama $\mathrm{Q}_{\max }$ 'ta $(-0,7 \mathrm{ml} / \mathrm{sn})$ ve $\mathrm{P}_{\text {det }} \mathrm{Q}_{\max }$ 'ta $\left(-7 \mathrm{~cm} \mathrm{H} \mathrm{H}_{2} \mathrm{O}\right)$ benzer bir fark, maksimum sistometrik kapasitede +67 ml'lik klinik açıdan önemsiz bir fark tespit edilmiştir. Tedaviyi tamamlayan hastaların \%87'sinin depolama semptomlarında gelişme sağlanmış olup antimuskarinik tedavinin tek başına MÇT'de güvenli olduğu belirtilmiştir (9). MÇT'li ve AAM'li hastalarda 6 aylık antimuskarinik monoterapi ile yapılan başka bir çalışmada 24 saatlik işeme sıklı̆g $19,8^{\prime}$ 'den 6,3'e, noktüri ise 4,1'den 2,9'a gerilemiş, AUA semptom skorunda ise 6,1'lik bir gerileme saptanmış ve hiçbir hastada akut üriner retansiyon (AUR) gelişmediği gözlenmiştir (10). MÇT ile AAM'nin birlikte görüldügü hastalarda antimuskarinik monoterapi çalışmalarının bulguları tatmin edici değildir. Tolterodin ve tamsulosin ile yapılan bir çalışmada AÜSS'li ve AAM'li hastalarda tolterodin monoterapisinde urge inkontinansta gelişme sağlanmış, fakat total IPSS'de, depolama subskorlarında ve hasta bazlı memnuniyet skorlarında plasebo ile karşılaştırıldığında herhangi bir fark saptanmamıştır (11). PSA $<1,3 \mathrm{ng} / \mathrm{ml}$ AÜSS ile AAM birlikte görülen hastalarda işeme sıklığı, urgency ve IPSS depolama skorlarında antimuskarinik monoterapi grubunda iyileşme olduğu saptanmış, fakat işeme IPSS skorlarında herhangi bir iyileşme saptanmamış ve AUR riskinin de artmadığ 1 tespit edilmiştir (12).

AÜSS ile AAM'nin birlikte görüldüğü, 40 yaş üzeri 879 hastada tolterodin ER ve tamsulosin + tolterodin ER kombinasyonu kullanılan randomize, kontrollü, çok merkezli bir çalışmada, prostat hacmi $<29 \mathrm{ml}$ olan kişilerde tolterodin monoterapisinin işeme sıklığı, urge üriner inkontinans ve IPSS depolama subskorlarında iyileşme sağladığı, $Q_{\max }$, PVR ve AUR’nin artmadığ 1 gösterilmiştir. Bu nedenle küçük prostat hacmine sahip, şiddetli ve orta dereceli AÜSS'li erkeklerin tedavisinde monoterapinin güvenle kullanabileceği savunulmuştur (13). MÇT olmayan, AAM ile ilgili olarak yapılan randomize, kontrollü, post hoc dört analiz çalışmasında (iki tolterodin ER, bir solifenasin $5 \mathrm{mg}$ ve bir fesoterodin 4 ve $8 \mathrm{mg}$ ); tolterodin ile ilgili olan çalışmada tedavi grubunda plasebo grubuna göre urge inkontinans ve 24 saatlik işeme sıklığında azalma; solifenasin ile ilgili olan çalışmada tedavi grubunda plasebo grubuna göre hasta bazlı mesane durum skorunda ve AAM sorgulama skorunda önemli gelişme; fesoterodin ile ilgili olan çalışmada ise tedavi grubunda plasebo grubuna göre işeme sıklığl, urgency sıklığ 1 ve urge inkontinans sıklığında önemli gelişme saptanmıştır (14-17). Bu çalışmalar göz önüne alınarak yapılan değerlendirmeye göre antimuskarinik monoterapinin AUR riskini minimal artırdığı kanaatinin yanında, prostat hacmi küçük, hafif obstrüksiyona sahip ve AAM semptomları baskın olan hastaların monoterapi için uygun hasta grubunu oluşturduğu ifade edilmektedir.

a1-Bloker ve antimuskarinik kombinasyon tedavisi

$a_{1}$-bloker ve antimuskarinik kombinasyon tedavisi teorik olarak uzun yıllar önce gündeme gelmiştir. Fakat bu konuda ilk kez 2003'te Athanasopoulos tarafindan detrüsör instabilitesinin eşlik ettiği MÇT’li hastalarda günde iki kez $2 \mathrm{mg}$ tolterodin ve $0,4 \mathrm{mg}$ tamsulosin kombinasyon tedavisi uygulanarak yaşam kalitesinde (QoL) düzelme sağlandığı ve tedaviye bağlı AUR riskinin artmadığı, antimuskarinik tedavinin idrar akımını ve rezidüel idrar volümünü etkilemediği ortaya konmuştur (18). Kanıt değeri yüksek fakat kısa takip süreli, çok merkezli, randomize, kontrollü, çift kör bir çalışmada, AAM'nin eşlik ettiği BPH'li hastalarda propiverin (20 mg/gün) ve doksazosin (4 mg/gün) kombinasyon tedavisinin değerlendirildiğinde, doksazosin alan gruba göre kombinasyon tedavisi uygulanan grupta IPSS depolama skorlarında, işeme sıklığında, işeme volümünde ve hasta memnuniyetinde gelişme tespit edilmiştir. PVR'de ortalama $+20,7 \mathrm{ml}$ klinik önemi olmayan bir artı̧̧ saptanmış, fakat hiçbir hastada AUR gelişmediği ifade edilmiştir (19). Kombinasyon tedavisinde antimuskarinik tedavinin zamanlaması ile ilgili olarak farklı görüşler bulunmaktadır. Lee ve 
Tablo 1. AÜSS tedavisinde kullanılan ilaçlar

\begin{tabular}{|l|l|l|l|}
\hline $\begin{array}{l}\boldsymbol{\alpha} \mathbf{1} \text {-adrenerjik reseptör } \\
\text { antagonistleri }\end{array}$ & Antimuskarinik ilaçlar & $\begin{array}{l}\mathbf{5} \boldsymbol{\alpha} \text {-redüktaz } \\
\text { inhibitörleri }\end{array}$ & Vazopressin analoğu \\
\hline $\begin{array}{l}\text { alfuzosin } \\
\text { doksazosin } \\
\text { terazosin } \\
\text { tamsulosin } \\
\text { silodosin }\end{array}$ & $\begin{array}{l}\text { darifenasin } \\
\text { trospiyumklorid } \\
\text { fesoterodin } \\
\text { oksibutinin } \\
\text { propiverin } \\
\text { solifenasin } \\
\text { tolterodin }\end{array}$ & $\begin{array}{l}\text { dutasterid } \\
\text { finasterid }\end{array}$ & desmopressin \\
\hline $\begin{array}{l}\text { al-adrenerjik reseptör antagonistleri } \\
+5 \alpha \text {-redüktaz inhibitörleri }\end{array}$ & $\begin{array}{l}\text { al-adrenerjik reseptör antagonistleri + } \\
\text { antimuskarinik ilaçlar }\end{array}$ & Fitoterapi & $\begin{array}{l}\text { Fosfodiasteraz tip 5 } \\
\text { inhibitörleri } \\
\text { tadalafil }\end{array}$ \\
\hline
\end{tabular}

arkadaşlarının basınç akım çalışmasında, AAM’nin eşlik ettiği MÇT'li hastalara üç ay süre ile doksazo$\sin (4 \mathrm{mg} /$ gün$)$ tedavisi uygulandıktan sonra hastaların sadece $\% 35$ 'inde semptomatik düzelme olduğu, semptomatik düzelme olmayan hastalarda 3 aylık ilave tolterodin (2 mg/gün) tedavisiyle başarının \%73’e çıktığı belirtilmiştir (20). Ardışık tedavinin aksine baştan kombine tedavi uygulanmasını savunan görüşler de bulunmaktadır. AAM ve BPH ile ilişkili AÜSS’si olan 50 yaş üzeri hastalarla yürütülen plasebo kontrollü, prospektif, randomize, çift kör bir çalışmada 12 haftalık (doksazosin+plasebo) ve (doksazosin+tolterodin) uygulaması sonrası yapılan değerlendirmede, kombine tedavi grubunda IPSS depolama semptom skorlarında, hasta bazlı QoL, urgency ve işeme sıklığında gelişme sağlanmış olup bir hastada AUR geliştiği belirtilmiştir. Aynı çalışmada $\mathrm{Q}_{\max }$ ve PVR'de gözlenen değişiklikler konusunda, doksazosin+plasebo grubunda $\mathrm{Q}_{\max }$ 'n ortalama $10,8 \mathrm{ml} /$ sn'den $15,3 \mathrm{ml} /$ sn'ye, PVR'nin ortalama 34 cc'den 24 cc'ye gerilediği, doksazosin+tolterodin grubunda ise $\mathrm{Q}_{\max }$ ' 1 11,1 ml/ sn'den 14,2 ml/sn'ye, PVR'nin de ortalama 33 cc'den 36 cc’ye yükseldiği gözlenmiş, fakat istatistiksel olarak bu değişimlerin anlamlılık göstermediği ortaya konmuştur (21). Antimuskarinik tedavinin etkinliğinin ve güvenilirliğinin değerlendirildiği plasebo kontrollü, prospektif, randomize, çift kör bir başka çalışmada (solifenasin+tamsulosin) ve (tamsulosin+plasebo) gruplarıyla 12 haftalık tedavi sonrasında kombine tedavi uygulanan grupta etkinlik açısından işeme sıklığ ve urgency atağında gerileme elde edilmiştir. Yan etki olarak ise kombine tedavi sonrası ağız kuruluğu \%7, baş dönmesi \%3, AUR \%3 olarak ortaya konmuştur (22). AÜSS nedeniyle $\alpha_{1}$-bloker kullanan hastalarda, AAM'ye bağlı depolama semptomları için uygulanan antimuskarinik tedavinin yan etkileri değerlendirildiğinde, ağız kuruluğu \%21, kabızlık \%6, dizüri \%3, AUR $\% 2$ ve kateterizasyon gerekliliği \%1 olarak tespit edilmiştir (23). Farklı antimuskarinik dozlar ile kombine tedavinin uygulandığı başka bir çalışmada; ürodinamik olarak incelendiğinde aktif tedavi gruplarında maksimum işemede detrüsör basıncı $\left(\mathrm{P}_{\operatorname{det}} \mathrm{Q}_{\max }\right)$ $\mathrm{H}_{2} \mathrm{O}$ 'da düşme, $\mathrm{Q}_{\max }$ 'ta artış gözlenmiş ve AUR riskinin artmadığı tespit edilmiştir. Fakat bu çalışmada PSA ve prostat hacimlerinin ölçülmemiş olması göz önünde bulundurulmalıdır (24). BPH'de $\alpha_{1}$-bloker ve antimuskarinik kombinasyon tedavisinin etkinlik ve güvenilirliği ile ilgili, 3.629 hastayı içeren ve ortalama tedavi süresinin 12 hafta olduğu geniş kapsamlı meta-analiz sonucunda, IPSS subkorlarında gerileme $(\Delta-0,73$, $95 \%$ CI $-1,09--0,37)$ ve işeme sıklığında azalma $(\Delta$ $-0,69$ işeme, $95 \% \mathrm{CI}-0,97--0,41), \mathrm{Q}_{\max }$ 'ta azalma $(\Delta-0,59 \mathrm{ml} / \mathrm{sn}, 95 \% \mathrm{CI}-1,04--0,14)$, PVR'de artış $(\triangle 11,60 \mathrm{ml}, 95 \% \mathrm{CI} 8,50-14,70)$ tespit edilmiş olup AUR oranının \%1,4, kateterizasyon gerekliliğinin ise $\% 0,5$ olduğu saptanmıştır. Bu meta-analiz sonucunda kombinasyon tedavisinin depolama semptomlarında gelişme sağladığı, PVR'yi minimal artırdığ 1 ve $Q_{\max }{ }^{1}$ minimal düşürdüğg̈ için BPH'ye bağlı AÜSS tedavisinde güvenli olduğu ifade edilmektedir (25). Yakın zamanda yapılmış olan ve AÜSS için $\alpha_{1}$-bloker + antimuskarinik ilaç kombinasyon tedavisi uygulanan 2.106 hasta $(\% 51,57)$ ve $\alpha_{1}$-bloker monoterapisi uygulanan 1.978 hasta $(\% 48,43)$ olmak üzere 18 randomize kontrollü çalışmadan toplam 4.084 hastayı ele alan bir meta-analizde; depolama IPSS, QoL, işeme sıkllğı/24s, urgency/24s bakımından kombinasyon tedavisinde gelişme olduğu saptanmış olup, $\mathrm{Q}_{\max }$ total IPSS, işeme IPSS için kombinasyon tedavisi ile $\alpha_{1}$-bloker monoterapisi arasında herhangi bir fark tespit edilmemiştir 
(26). Bu meta-analiz sonucunda depolama semptomları yoğun olan BPH/AÜSS'li hastalarda AUR riski göz önünde bulundurularak $\alpha_{1}$-bloker tedavisine ilave antimuskarinik tedavinin uygulanabileceği ifade edilmektedir.

Son olarak AUA'nın BPH ile ilgili kılavuzlarında; depolama semptomlarının baskın olduğu ve PVR'nin yüksek olmadığı BPH'ya bağlı AÜSS'lerin tedavisinde antimuskarinik ajanların uygun alternatif tedavi olabileceği, ancak antimuskarinik tedaviye başlamadan önce PVR'nin değerlendirilmesi gerektiği ve 250-300 ml'den fazla ise dikkatli olunması gerektiği bildirilmektedir. BPH/AÜSS'nin antimuskarinik ajanlarla tedavisinde PSA ölçümünün gerekli olmadığı kılavuzlarda belirtilmektedir (27). EAU'nun BPH'ya bağlı AÜSS ile ilgili kılavuzlarında ise kombinasyon tedavisinin PVR'yi artırdığı, AUR riskinin ise düşük olduğu belirtilmektedir. Şiddetli ve orta derecede AÜSS'li hastalarda eğer monoterapi yetersiz kalırsa antimuskarinik ajanlarla $\alpha_{1}$-blokerlerin kombine edilebileceği ve MÇT'li hastalarda ise kombinasyon tedavisinde dikkatli olunması gerektiği bildirilmektedir (28).

Sonuç olarak BPH'ye bağlı AÜSS'lerin tedavisinde $a_{1}$-bloker + antimuskarinik ilaç kombinasyon tedavisi IPSS depolama subskorları, QoL, işeme sıklığı ve urgency sıklığında iyileşmeye, PVR ve AUR riskinde ise minimal bir artışa neden olduğu için dikkatli olunması gerekmektedir. Depolama ile ilgili AÜSS'lerin baskın ve prostat hacminin $<40 \mathrm{ml}$ olması halinde antimuskarinik monoterapi uygulanması, prostat hacminin $>40$ $\mathrm{ml}$ olması ve $\alpha_{1}$-bloker ile tedaviye rağmen depolama semptomlarının devam etmesi halinde ise antimuskarinik ajanlarla kombinasyon tedavisi uygulanması gerekmektedir.

\section{KAYNAKLAR}

1. Oelke M, Bachmann A, Descazeaud A, Emberton M, Gravas S, Michel MC, et al. EAU guidelines on the treatment and follow-up of non-neurogenic male lower urinary tract symptoms including benign prostatic obstruction. Eur Urol. 2013;64(1):118-40.

2. Abrams P, Cardozo L, Fall M, Griffiths D, Rosier P, Ulmsten $\mathrm{U}$, et al. The standardisation of terminology of lower urinary tract function: report from the Standardisation Sub-committee of the International Continence Society. Neurourol Urodyn. 2002;21(2):167-78.
3. Kaplan SA, Bowers DL, Te AE, Olsson CA. Differential diagnosis of prostatism: a 12-year retrospective analysis of symptoms, urodynamics and satisfaction with therapy. J Urol. 1996;155(4):1305-8.

4. Hyman MJ, Groutz A, Blaivas JG. Detrusor instability in men: correlation of lower urinary tract symptoms with urodynamic findings. J Urol. 2001;166(2):550-2.

5. Coyne KS, Sexton CC, Vats V, Thompson C, Kopp ZS, Milsom I. National community prevalence of overactive bladder in the United States stratified by sex and age. Urology. 2011;77(5):1081-7.

6. Chapple CR, Roehrborn CG. A shifted paradigm for the further understanding, evaluation, and treatment of lower urinary tract symptoms in men: focus on the bladder. Eur Urol. 2006;49(4):651-9.

7. Chess-Williams R, Chapple CR, Yamanishi T, Yasuda K, Sellers DJ. The minor population of M3-receptors mediate contraction of human detrusor muscle in vitro. J Auton Pharmacol. 2001;(5-6) 21:243-8.

8. Matsui M, Motomura D, Karasawa H, Fujikawa T, Jiang J, Komiya Y, et al. Multiple functional defects in peripheral autonomic organs in mice lacking muscarinic acetylcholine receptor gene for the M3 subtype. Proc Natl Acad Sci USA. 2000;97(17):9579-84.

9. Abrams P, Kaplan S, De Koning Gans HJ, Millard R. Safety and tolerability of tolterodine for the treatment of overactive bladder in men with bladder outlet obstruction. J Urol. 2006;175(3):999-1004.

10. Kaplan SA, Walmsley K, Te AE. Tolterodine extended release attenuates lower urinary tract symptoms in men with benign prostatic hyperplasia. J Urol. 2005;174(6):2273-5.

11. Kaplan SA, Roehrborn CG, Rovner ES, Carlsson M, Bavendam T, Guan Z. Tolterodine and tamsulosin for treatment of men with lower urinary tract symptoms and overactive bladder: a randomized controlled trial. JAMA. 2006; 296(19):2319-28.

12. Roehrborn CG, Kaplan SA, Kraus SR, Wang JT, Bavendam T, Guan Z. Effects of serum PSA on efficacy of tolterodine extended release with or without tamsulosin in men with LUTS, including OAB. Urology. 2008;72(5):1061-7.

13. Roehrborn CG, Kaplan SA, Jones JS, Wang JT, Bavendam T, Guan Z. Tolterodine extended release with or without tamsulosin in men with lower urinary tract symptoms including overactive bladder symptoms: effects of prostate size. Eur Urol. 2009;55(2):472-9.

14. Roehrborn CG, Abrams P, Rovner ES, Kaplan SA, Herschorn S, Guan Z. Efficacy and tolerability of tolterodine extended-release in men with overactive bladder and urgency incontinence. BJU Int. 2006;97(5):1003-6.

15. Kaplan SA, Roehrborn CG, Dmochowski R, Rovner ES, Wang JT, Guan Z. Tolterodine extended release impro- 
ves overactive bladder symptoms in men with overactive bladder and nocturia. Urology. 2006;68(2):328-32.

16. Jones JS, Oelke M, MacDiarmid S, Wang JT, Guan Z. Efficacy and tolerability of fesoterodine in men with overactive bladder: a pooled analysis of 2 phase III studies. Urology. 2010;75(5):1149-55.

17. Kaplan SA, Goldfischer ER, Steers WD, Gittelman M, Andoh M, Forero-Schwanhaeuser S. Solifenacin treatment in men with overactive bladder: effects on symptoms and patient-reported outcomes. Aging Male. 2010;13(2):100-7.

18. Athanasopoulos A, Gyftopoulos K, Giannitsas K, Fisfis J, Perimenis P, Barbalias G. Combination treatment with an alpha-blocker plus an anticholinergic for bladder outlet obstruction: a prospective, randomized, controlled study. J Urol. 2003;169(6):2253-6.

19. Lee KS, Choo MS, Kim DY, Kim JC, Kim HJ, Min KS, et al. Combination treatment with propiverine hydrochloride plus doxazosin controlled release gastrointestinal therapeutic system formulation for overactive bladder and coexisting benign prostatic obstruction: a prospective, randomized, controlled multicenter study. J Urol. 2005;174(4):1334-8.

20. Lee JY, Kim HW, Lee SJ, Koh JS, Suh HJ, Chancellor MB. Comparison of doxazosin with or without tolterodine in men with symptomatic bladder outlet obstruction and an overactive bladder. BJU Int. 2004;94(6):817-20.

21. Lee SH, Chung BH, Kim SJ, Kim JH, Kim JC, Lee JY. Initial combined treatment with anticholinergics and a-blockers for men with lower urinary tract symptoms related to $\mathrm{BPH}$ and overactive bladder: a prospective, randomized, multi-center, double-blind, placebo-controlled study. Prostate Cancer Prostatic Dis. 2011;14(4):320-5.
22. Kaplan SA, McCammon K, Fincher R, Fakhoury A, He W. Safety and tolerability of solifenacin add-on therapy to alpha-blocker treated men with residual urgency and frequency. J Urol. 2009;182(6):2825-30.

23. Kaplan SA, Roehrborn CG, Gong J, Sun F, Guan Z. Addon fesoterodine for residual storage symptoms suggestive of overactive bladder in men receiving a-blocker treatment for lower urinary tract symptoms. BJU Int. 2012;109(12):1831-40.

24. Kaplan SA, He W, Koltun WD, Cummings J, Schneider T, Fakhoury A. Solifenacin plus tamsulosin combination treatment in men with lower urinary tract symptoms and bladder outlet obstruction: a randomized controlled trial. Eur Urol. 2013;63(1):158-65.

25. Filson CP, Hollingsworth JM, Clemens JQ, Wei JT. The efficacy and safety of combined therapy with $\alpha$-blockers and anticholinergics for men with benign prostatic hyperplasia: a meta-analysis. J Urol. 2013;190(6):215360.

26. Hao N, Tian Y, Liu W, Wazir R, Wang J, Liu L, et al. Antimuscarinics and $\alpha$-blockers or $\alpha$-blockers monotherapy on lower urinary tract symptoms-a meta-analysis. Urology. 2014;83(3):556-62.

27. McVary KT, Roehrborn CG, Avins AL, Barry MJ, Bruskewitz RC, Donnell RF, et al. Update on AUA guideline on the management of benign prostatic hyperplasia. J Urol. 2011;185(5):1793-803.

28. Gratzke C, Bachmann A, Descazeaud A, Drake MJ, Madersbacher S, Mamoulakis C, et al. EAU Guidelines on the Assessment of Non-neurogenic Male Lower Urinary Tract Symptoms including Benign Prostatic Obstruction. Eur Urol. 2015; 67(6):1099-109. 